\title{
Full scale evaluation of diffuser ageing with clean water oxygen transfer test
}

\author{
J. Krampe
}

\begin{abstract}
South Australian Water Corporation, 250 Victoria Square, Adelaide SA 5000, Australia (E-mail: joerg.krampe@sawater.com.au), former Institute for Sanitary Engineering, Water Quality and Waste Management (ISWA), University of Stuttgart, Germany
\end{abstract}

\begin{abstract}
Aeration is a crucial part of the biological wastewater treatment in activated sludge systems and the main energy user of WWTPs. Approximately 50 to $60 \%$ of the total energy consumption of a WWTP can be attributed to the aeration system. The performance of the aeration system, and in the case of fine bubble diffused aeration the diffuser performance, has a significant impact on the overall plant efficiency.

This paper seeks to isolate the changes of the diffuser performance over time by eliminating all other influencing parameters like sludge retention time, surfactants and reactor layout. To achieve this, different diffusers have been installed and tested in parallel treatment trains in two WWTPs. The diffusers have been performance tested in clean water tests under new conditions and after one year of operation. A set of material property tests describing the diffuser membrane quality was also performed.

The results showed a significant drop in the performance of the EPDM diffuser in the first year which resulted in similar oxygen transfer efficiency around $16 \mathrm{~g} / \mathrm{m}^{3} / \mathrm{m}$ for all tested systems. Even though the tested silicone diffusers did not show a drop in performance they had a low efficiency in the initial tests. The material properties indicate that the EPDM performance loss is partly due to the washout of additives.
\end{abstract}

Keywords Aeration systems, membrane diffuser, diffuser ageing, oxygen transfer

\section{INTRODUCTION}

For many years there has been a worldwide trend towards the use of fine bubble membrane diffusers which has mainly been driven by their higher efficiencies (Stenstrom et al., 1984). However, several practical tests show that surface aeration systems have a similar performance under operation, particularly for small WWTPs (Frey, 2001; Bagg et al., 2009). There is a variety of different diffuser constructions and materials available. The objective of current diffuser developments has been the reduction of the pressure loss of the diffuser and thereby the reduction of the WWTPs energy consumption.

Lately, many operators of wastewater treatment plants reported problems relating to fine bubble membrane diffusers which can be mainly differentiated into long term diffusers ageing (Rosso et al., 2008; Rosso and Stenstrom, 2006; Bagg et al., 2009) and short term diffuser clogging and fouling (Frey and Thonhauser, 2004; Wagner, 2001 and 2004). While the diffuser clogging and fouling usually has a direct impact on the backpressure of the system, the diffuser ageing can also result in a loss of performance which is not always obvious. As a result, consultants and utilities have an ongoing uncertainty regarding the correct selection of diffusers.

The concept of the presented project was to install new diffusers on two municipal WWTPs with several parallel treatment trains and examine them whilst new and after one year of operation. This rarely happens as aeration systems are usually tested once in clean water or under operational conditions and never again. The aim of the study was to compare the performance and material properties of various diffuser materials. Along with the development of the pressure loss, the change in oxygen transfer efficiency was measured in clean water tests. This approach ensures that the results

CIWA Publishing 2011. The definitive peer-reviewed and edited version of this article is published in Water Science \& Technology, Volume 64, Issue 3, 700-707, 2011, doi:10.2166/wst.2011.694 and is available at www.iwapublishing.com. This is the accepted version. 
are not changing with changes in the wastewater composition over the period of the study which would have been the case if off gas tests were selected. This paper presents the results of the oxygen transfer tests and selected results for the material properties.

\section{TEST METHODS}

\section{Oxygen transfer tests}

The oxygen transfer efficiency measurements were carried out in clean water according to the specifications of DIN EN 1225515 (2003) and the ATV advisory leaflet M 209E (1996). This method was chosen to measure solely the impact of the changing diffuser performance as outlined earlier. The reactors were drained and cleaned thoroughly for the purpose of the tests. The used diffusers were hosed down to remove sludge from the surface. Groundwater was used for the tests and examined for suitability in advance. Tests were conducted as absorption measurements. The DO concentration was lowered to approximately $0 \mathrm{mg} / \mathrm{L}$ by the addition of anhydrous, technical sodium sulphite. Starting from this low oxygen concentration in the reactor the aeration was turned on. The following increase of DO was recorded. The test was continued until the DO was constant for about 20 minutes.

Six DO electrodes with a fast response time were installed at two measurement points at different depths for each test. Each measurement was a double determination according to ATV (1996). Measurements and measuring points that differ by more than $10 \%$ of the mean were not considered for the evaluation.

\section{Investigation of material properties}

In addition to the oxygen transfer test, the material properties of the diffuser membranes and their changes were measured. The material analyses were carried out in cooperation with the IKP (Institute for Polymer Technology, University of Stuttgart, Germany). For each trial the mechanical properties of the diffuser membranes (hardness, tensile strength and elongation) were explored. Therefore stress strain behaviour and Shore A hardness tests were carried out. Similar tests were used by other groups (e.g. Frey, 2006, Kaliman et al., 2008) to measure the ageing of diffuser membranes. The stress strain tests were conducted according to DIN 53504. For these tests the sample preparation is very important, because the results differ depending on the different directions of the perforation. The test only produces reproducible and meaningful results if the slits are arranged in parallel to the central part of the sample. Figure 1 (left side) shows the preparation of the samples for different diffuser types. A tension testing machine was used for the tests (Figure 1, right side). The sample was concluded with a speed of $500 \mathrm{~mm} /$ minute for tube diffusers and $200 \mathrm{~mm} / \mathrm{minute}$ for disc diffusers with a force of 2 Newton. The storage of samples and the tests were carried out under standard conditions according to DIN EN ISO 291-23/50-2. Of interest for future considerations are the tensile strength and the ultimate elongation. Additionally Shore A hardness testing was performed at the IKP with the same samples. The tests were carried out in accordance with DIN 53505. This test was performed in a non-slit area of the diffuser membrane.

In addition, scanning electron microscopy (SEM) recordings with energy dispersive x-ray spectroscopy (EDX) were made in the inner surface of the slits. This method uses the SEM electron beam to stimulate the sample to emit characteristic X-rays which are then detected. This provides information about the basic chemical composition of the sample. This method was selected to examine potential material changes and scaling in the slits in more detail.

CIWA Publishing 2011. The definitive peer-reviewed and edited version of this article is published in Water Science \& Technology, Volume 64, Issue 3, 700-707, 2011, doi:10.2166/wst.2011.694 and is available at www.iwapublishing.com. This is the accepted version. 
To evaluate the extent of the clogging and visualize any pollution of the slits, reflected light microscopy recordings were conducted at the ISWA. New and used diffusers were examined under the microscope and photos taken.

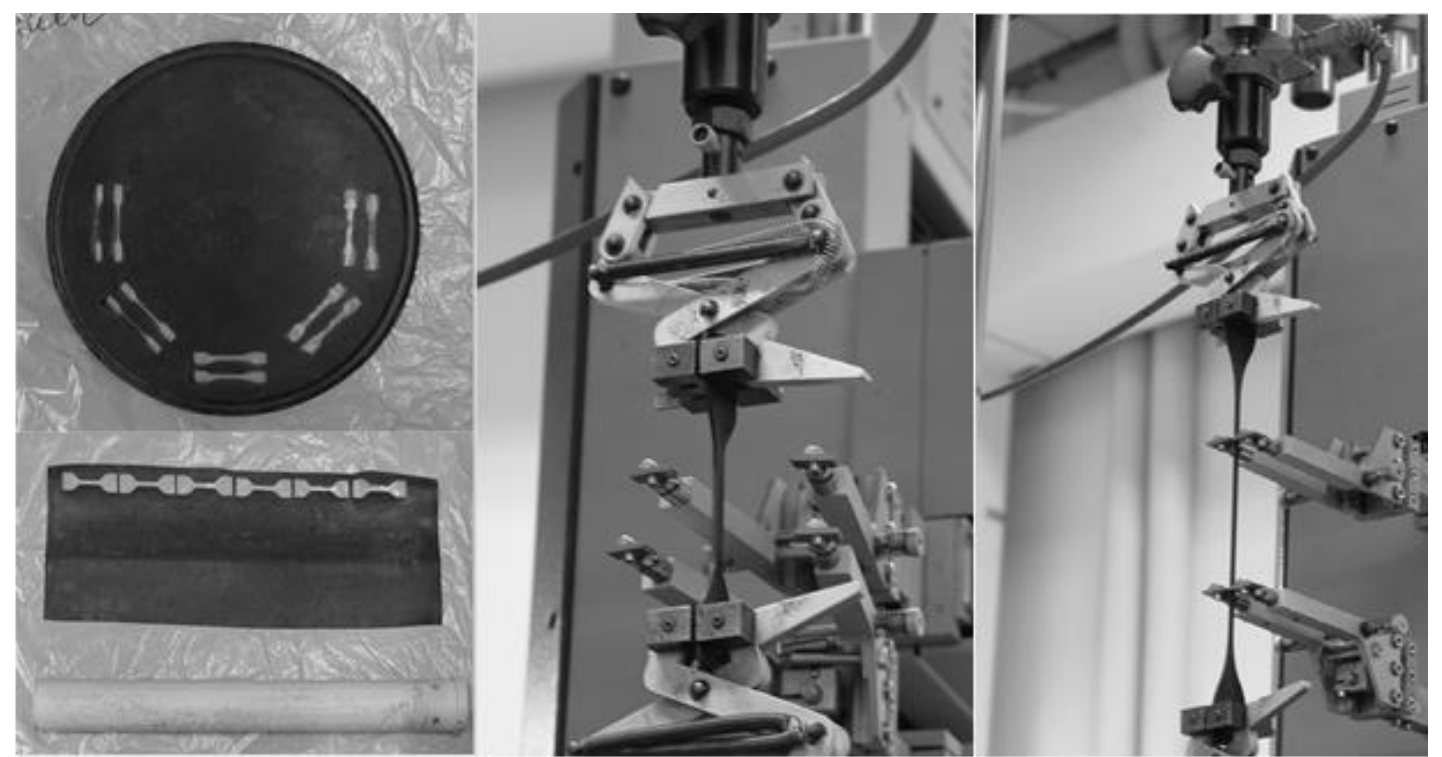

Figure 1: $\quad$ Material sampling method from disc (left top) and tube diffusers (left bottom) and implementation of the stress strain tests (right)

\section{DESCRIPTION OF THE EXAMINED DIFFUSERS AND WWTPS}

\section{Tests at Heilbronn WWTP (Germany)}

The sewage treatment plant Heilbronn has a design capacity of 500,000 PE. The average daily flow is $85,000 \mathrm{~m}^{3} / \mathrm{d}$. The mechanical treatment including primary sedimentation is followed by a biological phosphorus removal stage. Then the wastewater is equally distributed into four treatment trains each of which is operated as Modified Ludzack Ettinger process with separate denitrification and nitrification in ditches. The total volume of the biological stage is approximately $112,000 \mathrm{~m}^{3}$. At a water depth of $7.90 \mathrm{~m}$, the volume per nitrification reactor is $8,240 \mathrm{~m}^{3}$. Under normal operation conditions the diffusers undergo a stretching or air-bumping programme during which they are loaded with maximum blower power and after that the whole pressure of the system is released.

The sewage treatment plant Heilbronn is equipped with disc diffusers. For this investigation, three of the four nitrification basins were equipped with new diffusers. The following materials were selected:

- Ethylene-Propylene-Diene Rubber (EPDM) disc diffuser as per original design (no information about the plasticiser content available)

- Plasticiser reduced EPDM disc diffuser (8\% plasticiser content)

- High Density Polyethylene (HDPE) disc diffuser

The EPDM membrane with reduced plasticiser content was selected as there were discussions about the loss of plasticiser being a major reason for EPDM membranes to experience accelerated ageing (Wagner, 2003). It was possible to simply change the membrane in the existing diffuser body. Silicone membranes were not accepted by the operators and could therefore not be considered. The HDPE diffusers were selected as they have a reduced pressure loss compared to membrane diffusers which has a positive effect on the energy consumption. They required a complete new installation

CIWA Publishing 2011. The definitive peer-reviewed and edited version of this article is published in Water Science \& Technology, Volume 64, Issue 3, 700-707, 2011, doi:10.2166/wst.2011.694 and is available at www.iwapublishing.com. This is the accepted version. 
on the reactor floor. At this stage the supplier did not install enough diffusers and as a result it was not possible to achieve the required oxygen transfer after the changeover in this tank. Therefore the HDPE diffusers have not been considered further.

Each setting was tested twice, under new conditions (after a sufficient pre aeration time) and after a year of regular operation. Only in the case of the plasticizer reduced EPDM disc diffuser the oxygen transfer efficiency test after one year of operation was interrupted by a partial shut-down of the blowers. The results of this evaluation were considered due to the plausibility checks of the data with the other trial (comparing the slope) until the incident. After a total of 2.5 years, the opportunity arose to test the tank with the conventional EPDM disc diffusers again. All tests were conducted as outlined before.

Table 1: $\quad$ Installed diffusers at Heilbronn WWTP

\begin{tabular}{lccc}
\hline & $\begin{array}{c}\text { Plasticiser reduced } \\
\text { EPDM disc diffuser }\end{array}$ & EPDM disc diffuser & HDPE disc diffuser \\
\hline No. of diffusers & 2,500 & 2,500 & 1,300 \\
Diffuser density & $\sim 10 \%$ & $\sim 10 \%$ & $\sim 6.5 \%$ \\
Specific air flow at & $\sim 3.3 \mathrm{~m}^{3} / \mathrm{h} / \mathrm{disc}$ & $\sim 3.3 \mathrm{~m}^{3} / \mathrm{h} / \mathrm{disc}$ & $\sim 6.1 \mathrm{~m} / \mathrm{h} / \mathrm{disc}$ \\
$100 \%$ blower capacity & $\sim$ & \\
\hline
\end{tabular}

\section{Tests at Stuttgart-Plieningen WWTP (Germany)}

The wastewater treatment plant Plieningen has a design capacity of $133,000 \mathrm{PE}$. The basins for this investigation were two of four alternately operated reactors. Each reactor is divided into two equal chambers separated by a gate valve. The tests were carried out in one chamber. With a water level in the basin of $6.56 \mathrm{~m}$, each reactor has a volume of 3,614 $\mathrm{m}^{3}$ which equates to1,807 $\mathrm{m}^{3}$ per chamber.

Plieningen WWTP is equipped with tube diffusers and performs no regular cleaning of the diffusers. Shortly before the investigation, one reactor had been equipped with HDPE tube diffusers. Originally the experimental concept envisaged providing these diffusers for another reactor for the investigation. The HDPE diffusers were intended to be the link between both plants as the discs and tubes had the same diffuser material and the same internal EPDM non return valve. However, the HDPE diffuser had problems under the alternating operation, so the trial setup had to be changed. Ultimately, the following diffusers were examined:

- EPDM tube diffusers (13\% plasticiser content)

- Silicone tube diffusers

Table 2: $\quad$ Installed diffusers at Plieningen WWTP

\begin{tabular}{lcc}
\hline & EPDM tube diffuser & Silicone tube diffuser \\
\hline No. of diffusers & 280 & 280 \\
Diffuser density* & $\sim 15.8 \%$ & $\sim 15.8 \%$ \\
Specific air flow at $100 \%$ blower capacity & $\sim 9.0 \mathrm{~m} / \mathrm{m} / \mathrm{h}$ & $\sim 9.0 \mathrm{~m} / \mathrm{m} / \mathrm{h}$ \\
\hline
\end{tabular}

* Calculated with the whole circumference of the tube

No problems were encountered in the implementation of oxygen transfer tests, so that for each type of diffuser two measurements under new and used conditions are available.

CIWA Publishing 2011. The definitive peer-reviewed and edited version of this article is published in Water Science \& Technology, Volume 64, Issue 3, 700-707, 2011, doi:10.2166/wst.2011.694 and is available at www.iwapublishing.com. This is the accepted version. 


\section{RESULTS AND DISCUSSION}

\section{Comparative assessment of oxygen transfer tests}

The results are compared based on the Specific Standard Oxygen Transfer Rate (SSOTR) in $\mathrm{g} / \mathrm{m}^{3} / \mathrm{m}$. In the subsequent Table 3, the results for the individual materials in new condition and after approximately one year of operation are summarised. The table also shows the result for the test after 2.5 years at Heilbronn WWTP. To give a benchmark for the results of the new diffusers, the reference values of Wagner (2000) are stated as well. All tested EPDM diffusers achieved values which are in the range for favourable conditions. Alone the investigated silicone tube diffusers achieved average performance. It has to be highlighted that all diffusers were tested after a sufficient time of pre aeration. Looking at the results after a year of operation, a significant decrease of SSOTR is obvious for all EPDM diffusers. Only the silicone tube diffuser showed an increase for the oxygen transfer. Regardless of the installation situation and the diffuser type, all systems achieve almost the same specific standard oxygen after one year of operation, although each started with different results. No further reduction had occurred after 1.5 additional years of operation. This situation is illustrated graphically in Figure 2.

Table 3: $\quad$ Comparison of the results of the oxygen transfer tests

\begin{tabular}{|c|c|c|c|c|}
\hline & \multicolumn{2}{|c|}{ Heilbronn WWTP } & \multicolumn{2}{|c|}{ Plieningen WWTP } \\
\hline & $\begin{array}{l}\text { Plasticiser reduced } \\
\text { EPDM disc }\end{array}$ & EPDM disc & EPDM tube & Silicone tube \\
\hline \multirow{5}{*}{$\begin{array}{l}\text { SSOTR } \mathrm{g} / \mathrm{m}^{3} / \mathrm{m} \text { new } \\
\text { SSOTR } \mathrm{g} / \mathrm{m}^{3} / \mathrm{m} \text { used } \\
\text { percentage change } \\
\text { SSOTR } \mathrm{g} / \mathrm{m}^{3} / \mathrm{m} \text { after } \\
2.5 \text { years }\end{array}$} & 22.5 & 19.4 & 20.1 & 14.4 \\
\hline & 16.9 & 16.3 & 14.4 & 16.0 \\
\hline & $-25 \%$ & $-16 \%$ & $-28 \%$ & $+11 \%$ \\
\hline & & 16.4 & & \\
\hline & \multicolumn{4}{|c|}{$\begin{array}{l}\text { Reference SSOTR values under clean water conditions (Wagner, 2000) } \\
\text { mixing and aeration } * \quad \text { area wide diffuser coverage } * *\end{array}$} \\
\hline favourable & \multicolumn{2}{|c|}{20.0} & \multicolumn{2}{|c|}{23.9} \\
\hline average & \multicolumn{2}{|c|}{15.0} & \multicolumn{2}{|c|}{17.9} \\
\hline
\end{tabular}

*Situation at Heilbronn WWTP, ** situation at Plieningen WWTP

The results align with the findings of Rosso et al. (2008) who reported a change in $\alpha$ or $\alpha \mathrm{F}$ in the same order of magnitude for new and used diffuser based on off-gas tests for similar plant configurations as tested here.

It has to be noted that the change of oxygen transfer efficiency was not indicated in an increasing pressure loss of the aeration system. This confirms a similar statement in US EPA Design Manual "fine pore aeration system" (US EPA, 1989). It shows that the backpressure does not provide a good guide to oxygen transfer efficiency reductions. These are best tracked by noting increases in the specific blower power consumption (e.g. $\mathrm{kWh} / \mathrm{kg} \mathrm{BOD}_{5}$ ).

As each test took place under comparable conditions (depth of submergence, air flow, clean water quality etc.) changes of the oxygen transfer efficiency can only be contributed to the diffuser performance. For this reason, some of the diffusers were removed and compared with retained samples of the new diffuser membranes. Periodic air-bumping did not appear to improve efficiencies and no efficiency loss differences could be determined between continuous or intermittently aerated systems.

CIWA Publishing 2011. The definitive peer-reviewed and edited version of this article is published in Water Science \& Technology, Volume 64, Issue 3, 700-707, 2011, doi:10.2166/wst.2011.694 and is available at www.iwapublishing.com. This is the accepted version. 


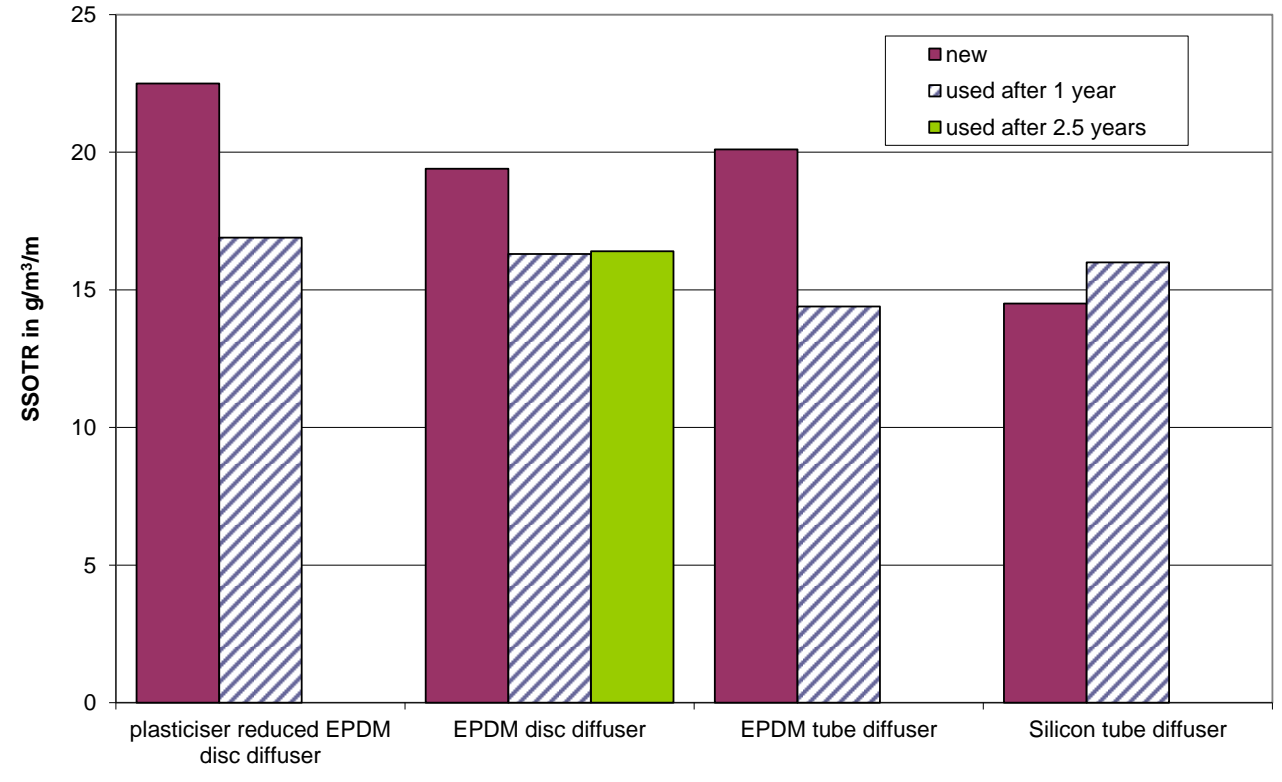

Figure 2: $\quad$ Specific Standard Oxygen Transfer Rate for all tests in comparison

\section{Comparative evaluation of material properties}

To assess the diffuser membranes, the tests outlined earlier were conducted. Table 4 show the results of the stress strain tests and the Shore A hardness determination.

Table 4: $\quad$ Results of the stress strain and hardness tests as a mean of 10 samples

\begin{tabular}{|c|c|c|c|c|c|c|c|c|}
\hline & \multicolumn{4}{|c|}{ Heilbronn WWTP } & \multicolumn{4}{|c|}{ Plieningen WWTP } \\
\hline & \multirow{2}{*}{$\begin{array}{c}\text { Plasticiser red. } \\
\text { EPDM disc } \\
\text { spec* }^{*}\end{array}$} & \multicolumn{3}{|c|}{ EPDM disc } & \multicolumn{2}{|c|}{ EPDM tube } & \multicolumn{2}{|c|}{ Silicone tube } \\
\hline & & new & used & $\begin{array}{c}2.5 \\
\text { years }\end{array}$ & new & used & new & used \\
\hline $\begin{array}{l}\text { Tensile strength } \\
\text { in } \mathrm{MPa}\end{array}$ & $>8$ & 7.9 & 7.3 & 3.7 & 10.3 & 11.0 & 10.9 & 10.6 \\
\hline $\begin{array}{l}\text { Max elongation } \\
\text { in } \%\end{array}$ & $>400$ & 424 & 410 & 268 & 747 & 747 & 673 & 665 \\
\hline $\begin{array}{l}\text { Hardness } \\
\text { in Shore A }\end{array}$ & $57 \pm 5$ & 52.3 & 54.0 & - & 51.0 & 52.7 & 55.7 & 56.0 \\
\hline
\end{tabular}

For all tested diffusers no significant differences in material behaviour and overall no signs of material deterioration were recognizable after one year of operation. However after 2.5 years of operation the EPDM disc diffuser showed slight cracks and the material deteriorated. This does not correlate with the oxygen transfer tests where the SSOTR dropped in the first year of operation but remained unchanged for the next 1.5 years of operation.

In Table 5 individual pictures from the reflected light microscopy of the various diffusers are presented. While the slits of the new diffusers had an even surface, there were strong differences in the blocking of the slits of the used diffusers. Particularly dirty slits were selected for the pictures. The

CIWA Publishing 2011. The definitive peer-reviewed and edited version of this article is published in Water Science \& Technology, Volume 64, Issue 3, 700-707, 2011, doi:10.2166/wst.2011.694 and is available at www.iwapublishing.com. This is the accepted version. 
blocking of the slits certainly represents one possible reason for the deterioration of the oxygen transfer efficiency. Similar experiences are for example reported by Frey and Thonhausen (2004). However, as the silicone diffuser also showed a similar blocking of the slits and at the same time increasing oxygen transfer efficiency, the blocking cannot be the sole cause for the deterioration.

Table 5: $\quad$ Reflected light microscopy photos

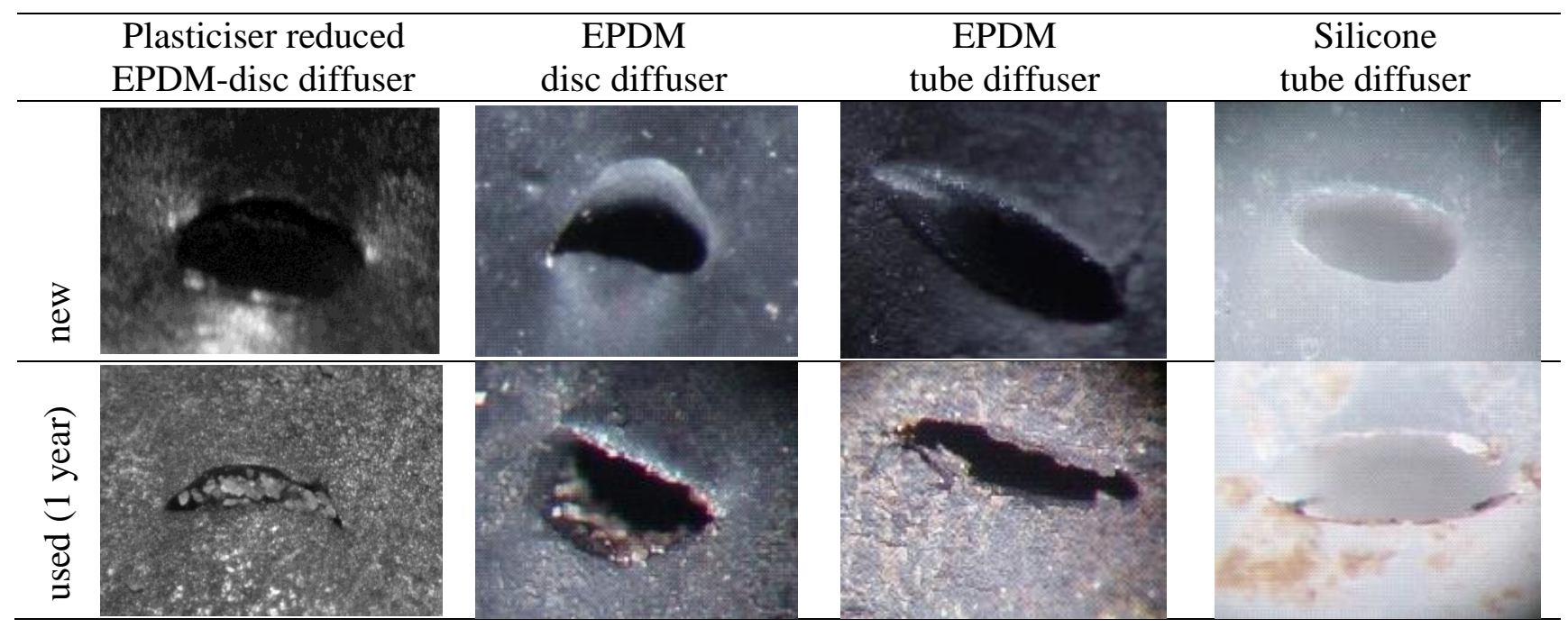

In addition to the reflected light microscopy, SEM micrographs of the slits were taken. Selected pictures of the new and used diffusers are compared in Table 6 . The diffuser membranes were cut lengthwise in the level of a slit series. The enlarged images are from the wall of the slits.

Table 6: $\quad$ Comparison of the SEM micrographs

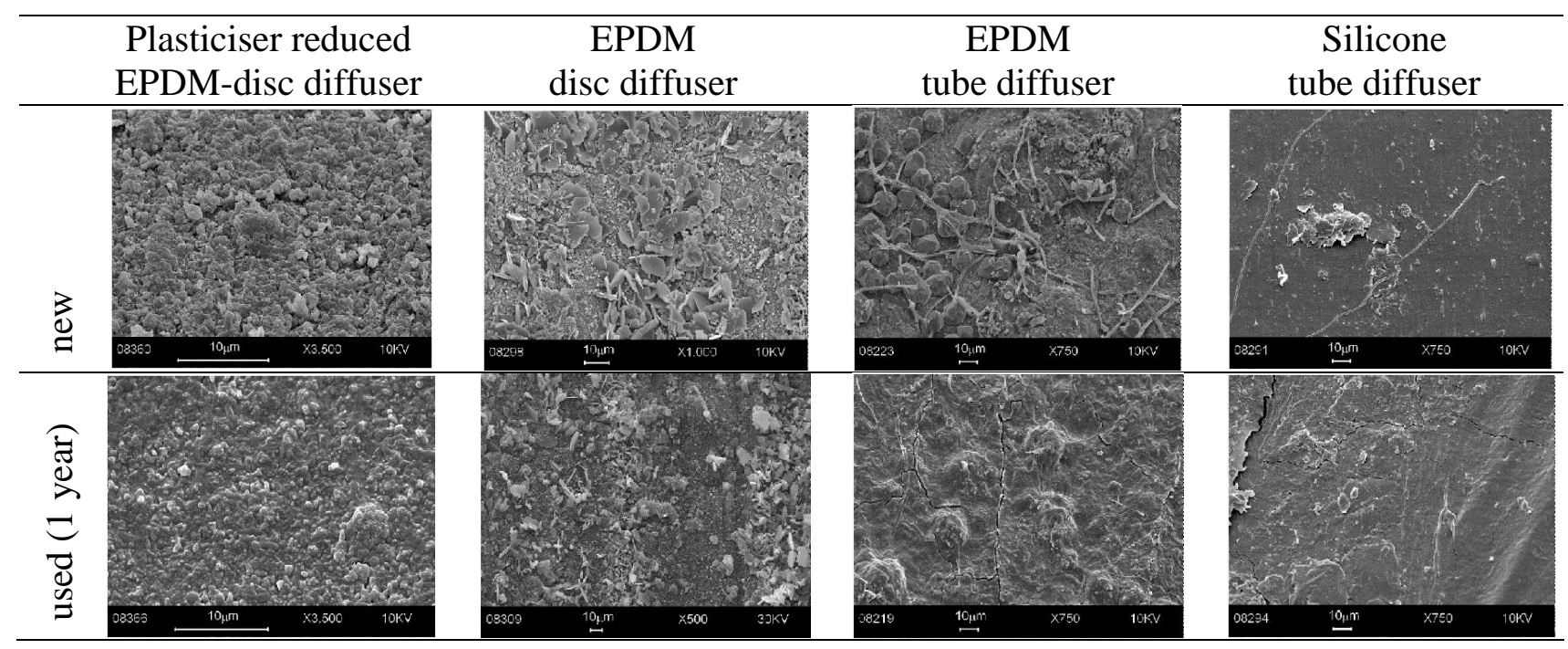

The SEM micrographs show that the slits of the EPDM diffuser membranes are significantly rougher than the examined silicone membrane slits. In new conditions, the EPDM diffusers have different additives etc attached to the slits which cause very rough slits. After one year of operation, the sections of the slits have become significantly smoother. With the silicone diffuser a reverse tendency can be recognised. Here, the inside of the slit has become slightly rougher in the first year. This is expected to be another reason for the change of the oxygen transfer efficiency apart from the generally observed clogging of slits.

CIWA Publishing 2011. The definitive peer-reviewed and edited version of this article is published in Water Science \& Technology, Volume 64, Issue 3, 700-707, 2011, doi:10.2166/wst.2011.694 and is available at www.iwapublishing.com. This is the accepted version. 
The EDX spectra indicate decreasing roughness of EPDM diffuser slits as a result of the attached additives being carried away during operation. Those additives (eg Sulphur, Calcium and Zinc) are used during the manufacturing of the membranes for example as extraction agent during the extrusion. It can be assumed that the existence of the individual substances itself does not lead to deterioration of the oxygen transfer efficiency but the changes of the release behaviour of bubbles in the diffusers. According to Bruss (2006), the bubble size depends on the nature of the membrane surface in the exit region of the air. The more hydrophilic the membrane surface is around the slit, the faster the bubbles detach as the water can enclose the bubble better. This can be attributed to physical causes through the modified roughness or modified hydrophilic behaviour of the diffusers. For assessing the hydrophilic properties of the different membranes, contact angle measurements of diffusers were carried out. These were inconclusive due to sample conservation issues for this specific test. Therefore these results are not presented here but it is suggested to consider these contact angle measurements for further trials.

\section{SUMMARY AND CONCLUSIONS}

Firstly, the results reinforce that oxygen transfer tests under new conditions in clean water represent only a current snapshot of the system. In most cases, a significant decrease of the oxygen transfer has to be expected. In this test all tested membranes showed a similar SSOTR of around $16 \mathrm{~g} / \mathrm{m}^{3} / \mathrm{m}$ after one year of operation and longer. The results indicate that changes in the material properties of the diffuser membrane are not the main influencing factor for the performance drop. The material properties only changed marginally after one year but more after 2.5 years. This does not correlate with the oxygen transfer tests where the SSOTR dropped in the first year of operation but remained unchanged for the next 1.5 years of operation.

The changes in terms of the oxygen transfer efficiency in this study cannot be attributed to a single cause. The measurements strongly suggest that fast deterioration of the EPDM diffuser performance in the first year can be attributed to the release of additives from the EPDM membrane slits and the blocking of slits. The release of additives seems to cause changes in the diffuser membrane surface properties. This has an effect on the oxygen transfer efficiency via the change in the release behaviour of bubbles in the diffusers. The assessment of the hydrophilic properties of the different membranes with contact angle measurements was inconclusive due to sample conservation issues for this specific test but it is suggested to consider contact angle measurements for further trials as the hydrophilic behaviour has to be regarded as a key influencing factor.

Several other conclusions can be drawn from this study; in comparing both plants, periodic airbumping did not appear to improve efficiencies. Significant efficiency losses could be determined for the continuous and intermittently aerated system apart from the silicon membrane. Also the plasticiser content of the EPDM membranes made no difference in this study. Even though equipped with internal non return valves HDPE diffusers were not appropriate for intermittent operation.

It can also be concluded that the pressure loss of the diffusers is not a reliable criterion for assessing membrane diffusers in operation. This is because in two examined treatment plants, the oxygen transfer efficiency dropped significantly after a year of operation despite an almost constant pressure loss of the membranes. A sufficient key performance indicator for the aeration systems needs to consider the specific power consumption of the blowers (e.g. $\mathrm{kWh} / \mathrm{kg} \mathrm{BOD}$ ) to pick up the changes in the oxygen transfer efficiency. For new aeration systems, higher oxygen transfer rates have to be demanded to ensure an adequate oxygen supply after several years of operation.

CIWA Publishing 2011. The definitive peer-reviewed and edited version of this article is published in Water Science \& Technology, Volume 64, Issue 3, 700-707, 2011, doi:10.2166/wst.2011.694 and is available at www.iwapublishing.com. This is the accepted version. 


\section{ACKNOWLEDGEMENTS}

This research was supported by the Ministry of the Environment, Nature Conservation and Transport Baden-Württemberg and carried out during my time at the Institute for Sanitary Engineering, Water Quality and Solid Waste Management (ISAW) of the University of Stuttgart.

\section{REFERENCES}

ATV (1996), Advisory Leaflet ATV - M 209E, Measurement of the Oxygen Transfer in Activated Sludge Aeration Tanks with Clean Water and in Mixed Liquor, German Association for the Water Environment, June 1996

Bagg, W., Puzey, D., Kendall G. (2009), The true cost of average aeration system design - some real facts and figures, Ozwater, 2009

Bruss, F. (2006), personal correspondence

Frey, W., Thonhauser, C. (2004), Clogging and cleaning of fine-pore membrane diffusers, Water Sci. Technol. 50 (7), 69-77

Frey, W. (2001), Einsatz von Oberflächenbelüftungssystemen - heute wieder gerechtfertigt? (Use of surface aeration system - justified again?), 64. Darmstädter Seminar Abwassertechnik, Neues zur Belüftungstechnik - Probleme, Lösungsmöglichkeiten, Entwicklungen, Schriftenreihe WAR 134, Darmstadt 2001

Frey, W. (2006), Einflüsse auf die Veränderung des Betriebsverhaltens von Membranbelüftern (Factors influencing the behaviour of membrane diffusers), Seminar Messverfahren für die Sauerstoffeintragsleistung in Belebungsbecken, Osnabrück, 2006

Kaliman, A., Rosso, D., Leu, S.Y., Strenstrom, M.K. (2008), Fine-pore aeration diffusers: Accelerated membrane ageing studies, Water Res. 42, 467 - 475

Rosso, D., Stenstrom, M.K. (2006), Economic implications of fine-pore diffuser ageing, Water Environment Federation, 78 (8), 810-815

Rosso, D., Larson, L.E., Stenstrom, M.K. (2008), Aeration of large-scale municipal wastewater treatment plants: state of the art, Water Sci. Technol. 57 (7), $973-978$

Stenstrom, M.K., Vazirinejad, H.O., Ng, A. (1984) Economic evaluation of upgrading aeration systems, J. Water Pollut. Control Fed. 56 (1), 20 - 26

US EPA (1989), Design Manual: Fine Pore Aeration Systems. EPA 625-1-89/023, 1989

Wagner, M. (2000) Sauerstoffeintrag in Abwasserbehandlungsanlagen - Leistungsfähigkeit von Belüftungssystemen (Oxygen transfer in WWTPs - Efficiency of aeration systems), Wasserkalender 2001 - Jahrbuch für das gesamte Wasserfach, Erich Schmidt Verlag, Berlin, 2000

Wagner, M. (2001) Darstellung von Schadensfällen durch belegte EPDM-Membranen und Lösungsmöglichkeiten (Cases of damages resulting from fouled EPDM membranes and possible solutions), Schriftenreihe WAR, Nr. 134, Darmstadt 2001

Wagner, M. (2003) Biological Coating of Fine Bubble Diffusers with EPDM-Membranes in: Proceedings WEFTEC 2003, Los Angeles

Wagner, M. (2004) Probleme mit Belagsbildung auf Membranen von Belüftungselementen - eine Übersicht (Fouling problems of membrane diffusers - an overview), 2. WAR - Infotag, Darmstadt 22. April 2004

CIWA Publishing 2011. The definitive peer-reviewed and edited version of this article is published in Water Science \& Technology, Volume 64, Issue 3, 700-707, 2011, doi:10.2166/wst.2011.694 and is available at www.iwapublishing.com. This is the accepted version. 